\title{
BMJ Open Systems approach to health service design, delivery and improvement: a systematic review and meta-analysis
}

\author{
Alexander Komashie (D) , ${ }^{1,2,3}$ James Ward, ${ }^{1}$ Tom Bashford (D) , ${ }^{1,3,4}$ Terry Dickerson, ${ }^{1}$ \\ Gulsum Kubra Kaya (D) , ${ }^{5}$ Yuanyuan Liu (D) , ${ }^{1}$ Isla Kuhn, ${ }^{6}$ Aslı Günay (D) , 1,7 \\ Katharina Kohler (D) , ${ }^{1,4}$ Nicholas Boddy, ${ }^{1,8}$ Eugenia O'Kelly (D) , ${ }^{1}$ Joseph Masters, ${ }^{9}$ \\ John Dean, ${ }^{10}$ Catherine Meads (D) , ${ }^{11} \mathrm{P}$ John Clarkson (i) ${ }^{1}$
}

To cite: Komashie A,

Ward J, Bashford T,

et al. Systems approach

to health service design,

delivery and improvement:

a systematic review and

meta-analysis. BMJ Open

2021;11:e037667. doi:10.1136/

bmjopen-2020-037667

- Prepublication history and supplemental material for this paper is available online. To view these files, please visit the journal online (http://dx.doi. org/10.1136/bmjopen-2020037667).

Received 19 February 2020 Revised 02 0ctober 2020 Accepted 18 November 2020

Check for updates

(C) Author(s) (or their employer(s)) 2021. Re-use permitted under CC BY-NC. No commercial re-use. See rights and permissions. Published by BMJ.

For numbered affiliations see end of article.

Correspondence to Dr Alexander Komashie; A.Komashie@eng.cam.ac.uk

\section{ABSTRACT}

Objectives To systematically review the evidence base for a systems approach to healthcare design, delivery or improvement.

Design Systematic review with meta-analyses.

Methods Included were studies in any patients, in any healthcare setting where a systems approach was compared with usual care which reported quantitative results for any outcomes for both groups. We searched Medline, Embase, HMIC, Health Business Elite, Web of Science, Scopus, PsycINFO and CINAHL from inception to 28 May 2019 for relevant studies. These were screened, and data extracted independently and in duplicate. Study outcomes were stratified by study design and whether they reported patient and/or service outcomes. Metaanalysis was conducted with Revman software V.5.3 using ORs-heterogeneity was assessed using $\mathrm{I}^{2}$ statistics. Results 0 f 11405 records 35 studies were included, of which $28(80 \%)$ were before-and-after design only, five were both before-and-after and concurrent design, and two were randomised controlled trials (RCTs). There was heterogeneity of interventions and wide variation in reported outcome types. Almost all results showed health improvement where systems approaches were used. Study quality varied widely. Exploratory meta-analysis of these suggested favourable effects on both patient outcomes ( $n=14,0 R=0.52$ (95\% Cl 0.38 to 0.71$\left.) I^{2}=91 \%\right)$, and service outcomes $(\mathrm{n}=18,0 \mathrm{R}=0.40(95 \% \mathrm{Cl} 0.31$ to 0.52) $\left.\right|^{2}=97 \%$ ).

Conclusions This study suggests that a systems approaches to healthcare design and delivery results in a statistically significant improvement to both patient and service outcomes. However, better quality studies, particularly RCTs are needed.

PROSPERO registration number CRD42017065920.

\section{INTRODUCTION}

The 20th and 21st centuries have witnessed the development of highly effective healthcare technologies, diagnoses and interventions. $^{12}$ Nonetheless, there remains a pressing need for improvement in both the quality and safety of care delivery. ${ }^{3-5}$ This is often attributed to several factors including
Strengths and limitations of this study

- This is the first systematic review to provide a comprehensive and transparent synthesis of the published evidence base for a systems approach to healthcare design, delivery and improvement.

- A major limitation of our study rests on the heterogeneity of the literature it seeks to synthesise, with wide variation in the settings, participants, comparators, follow-up durations and study designs.

- We have conducted two exploratory meta-analyses in order to give an overview of the general direction of results, and we acknowledge that these may give artificial numerical precision which may not be warranted.

- This benefit must be interpreted and applied with care because the evidence mostly comes from before-and-after study designs, with inherent confounding factors of unknown magnitude and direction.

- Several included studies reported both the potential of a Hawthorne effect and the existence of other interventions at the time of their study which may have contributed to their observed outcomes.

multimorbidity, ${ }^{6}$ the complexity of healthcare delivery $^{7}$ and a variety of cultural and organisational challenges. ${ }^{89}$ Drawing on the experience of fields such as engineering and design a 'systems approach' to improvement has been advocated, that recognises the interacting components of healthcare delivery, the people involved, as well as planned, considered and adaptive iterative implementation. ${ }^{10-16}$ However, there has not been a systematic review of the evidence base for such an approach within the healthcare literature to date.

Modern healthcare systems are striving for integrated, patient-centred, effective and efficient care, ${ }^{17}$ but the lesson from engineering is that such systems do not happen by accident; they need to be planned, designed 
and built. ${ }^{18}$ Understanding what this process might look like has been explored with reference to the literature on patient safety, ${ }^{19}$ Human Factors and Ergonomics (HFE) ${ }^{20}$ general practice,${ }^{21}$ the well-being of healthcare workers ${ }^{22}$ and public health. ${ }^{23}$ These reviews, while useful, are limited in their scope and employ narrow views of a systems approach.

The primary objective of this study is to review, comprehensively, the usefulness of a systems approach to healthcare improvement. There were no limits on language, participant types, outcome types or any particular healthcare domain.

\section{Definition of a systems approach}

Defining a systems approach is challenging. The approach has origins in a variety of disciplines, which have both diverged and converged over the past century. These range from mathematics to social science, and span both the physical and biological sciences. ${ }^{24}$ In order to arrive at a definition that we could operationalise for the purpose of this systematic review, the team reviewed definitions of a systems approach including Clarkson $e t a l,{ }^{10}$ Maier and Rechtin, ${ }^{25}$ Chen ${ }^{26}$ and the NASA systems engineering handbook. ${ }^{27}$ As a result, we developed a shared understanding of a system, at its fundamental level, as:

A collection of different elements (or things) which together produce results unachievable by the individual elements on their own. ${ }^{28}$

Our working definition of a systems approach, which has been informed by Clarkson et al,${ }^{10}$ is as follows:

A systems approach to healthcare improvement is a way of addressing health delivery challenges that recognises the multiplicity of elements interacting to impact an outcome of interest and implements processes or tools in a holistic way.

This view of a systems approach integrates perspectives on people, systems, design and risk in a way that is applicable to healthcare systems across all scales from local service systems through to organisational, crossorganisational and national policy levels.

\section{METHODS}

This systematic review was conducted and reported in accordance with the Preferred Reporting Items for Systematic Reviews and Meta-Analyses (PRISMA) standard. ${ }^{29}$

Included were published primary research studies involving any patients in any healthcare setting where a systems approach was compared with concurrent or historical comparators-usual care or a non-systems approach, which reported numerical results for both groups for any outcomes relevant to the study being conducted. Excluded were conference reports or other unpublished studies, studies without clear evidence of a systems approach being used, studies without any type of comparator or studies without quantitative outcome data for either group.

\section{Information sources}

We searched the following databases with no limits on date of publication: Medline, Embase and HMIC (via OVID), Health Business Elite, PsycINFO and CINAHL (via EBSCO), Web of Science and Scopus. The search was first conducted in August 2017 and repeated on 28 May 2019. It was repeated for a second time on 24 July 2020, but we found very little additional evidence, in particular nothing that would affect the meta-analysis direction and the conclusions of the systematic review. As a result, the analysis and results presented here are based studies up to May 2019. There were no limits on language, participant types, outcome types or any healthcare domain. The full search strategy including specific search strings are provided in online supplemental file 1 .

\section{Study selection process}

We used a structured, two-stage approach to determine inclusion. The first stage involved a title/abstract review of citations after removing duplicates. The second consisted of a full-text review of the 107 papers identified as potential for inclusion.

For the title/abstract review stage, three pairs of researchers looked at a third of the records each. Studies were selected for inclusion or rejection independently by each researcher, and with differences resolved first within the pair, and then within the whole team where the pair could not agree.

The full-text review stage applied the definition of a system and of a systems approach as stated above. Researcher pairs individually reviewed studies for inclusion or exclusion based on the following two questions:

1. Does the study identify a clear problem framed in a systems context and demonstrate the use of a systems approach, in some way? AND

2. Does the study have an appropriate design to address the research question?

Question one excluded any study which did not in some way demonstrate a systems approach in its formulation and/or implementation of an improvement intervention, while question two excluded all protocols, conference abstracts, systematic reviews, reviews, editorials and any paper with no primary research or no comparator arm.

Following the individual assessment, members of each pair discussed their results to arrive at a consensus on which studies to include. As a final check for all included studies, the team assessed each study against aspects of our working definition of a systems approach. Studies were assessed on a binary scale ( 0 or 1$)$ as to whether they demonstrate a consideration of systems in the development of an intervention or in the implementation of the intervention, use of design and a consideration of risk. The outcome of this assessment is shown in table 1 in online supplemental file 2. A full list of excluded studies with reasons for exclusion is also provided in online supplemental file 3. Our method is also summarised using the PRISMA systematic review process shown in figure 1. 

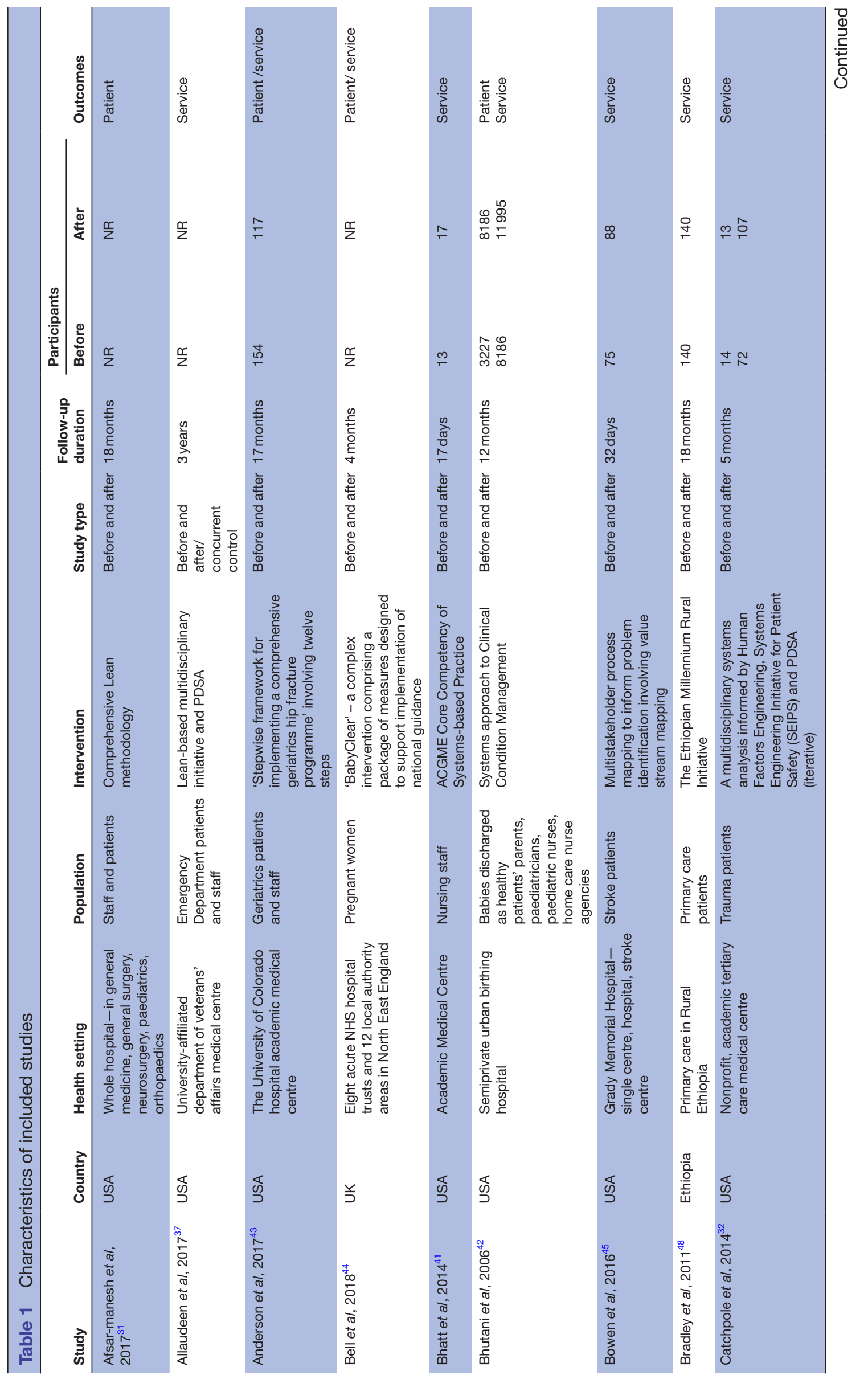

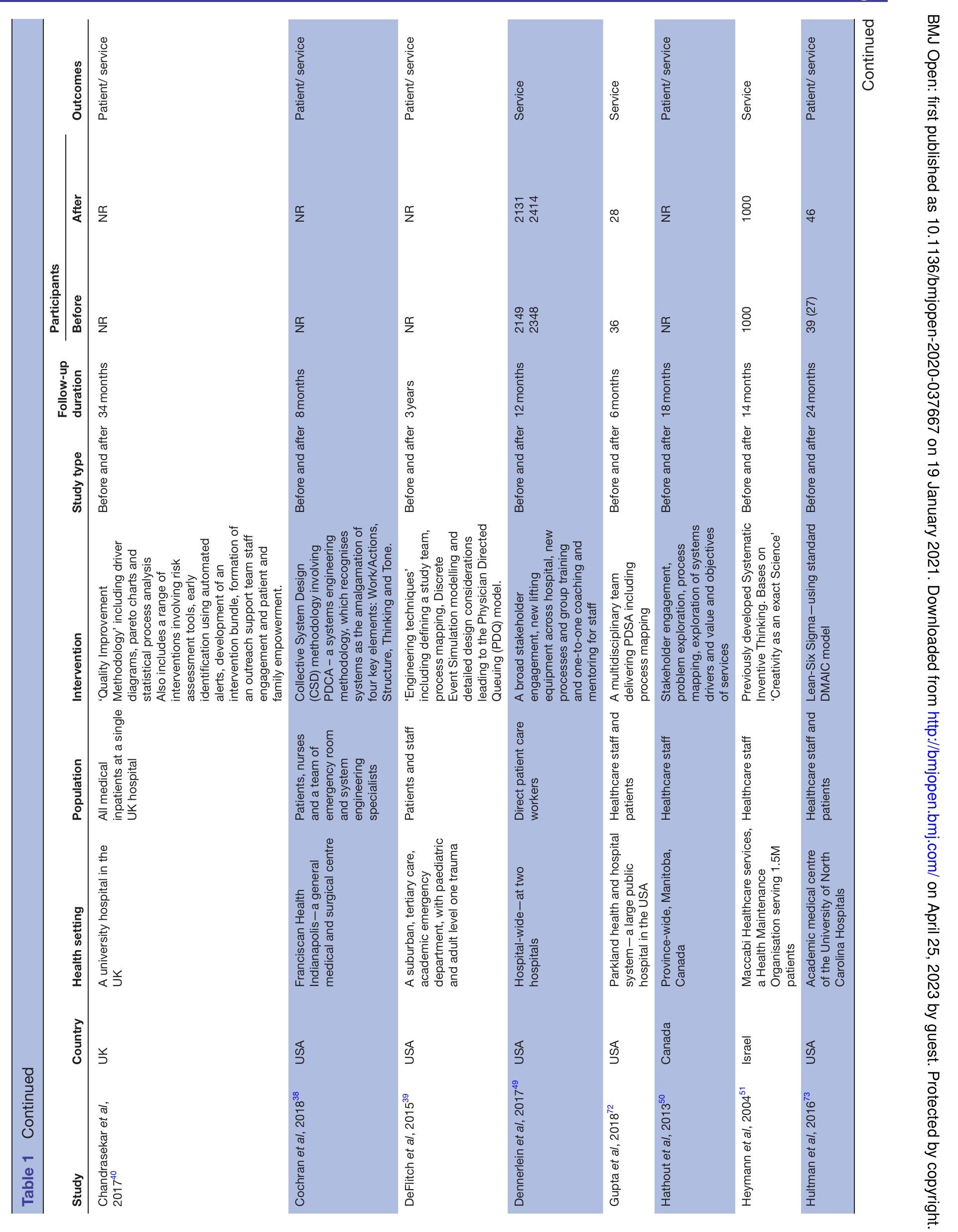

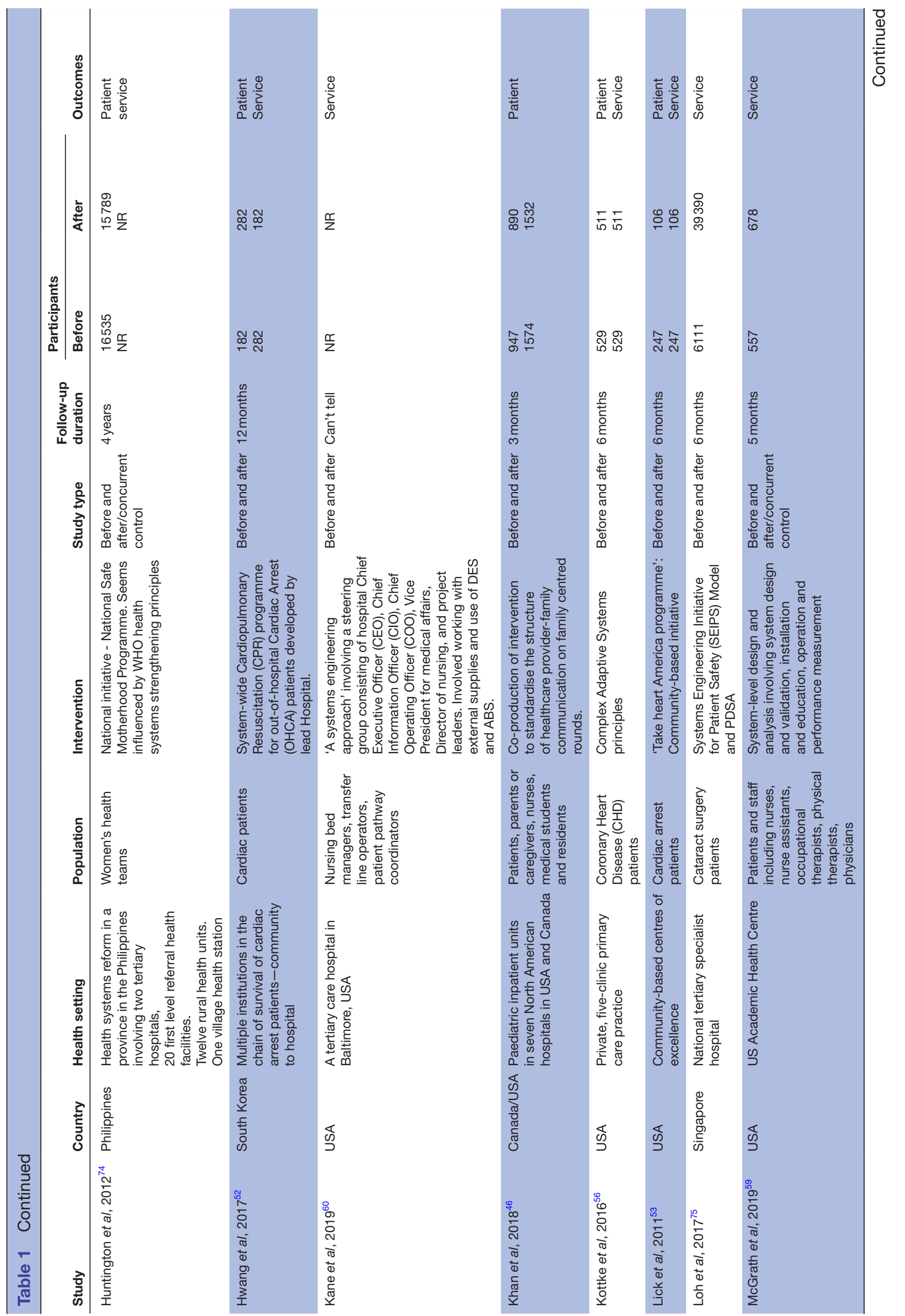


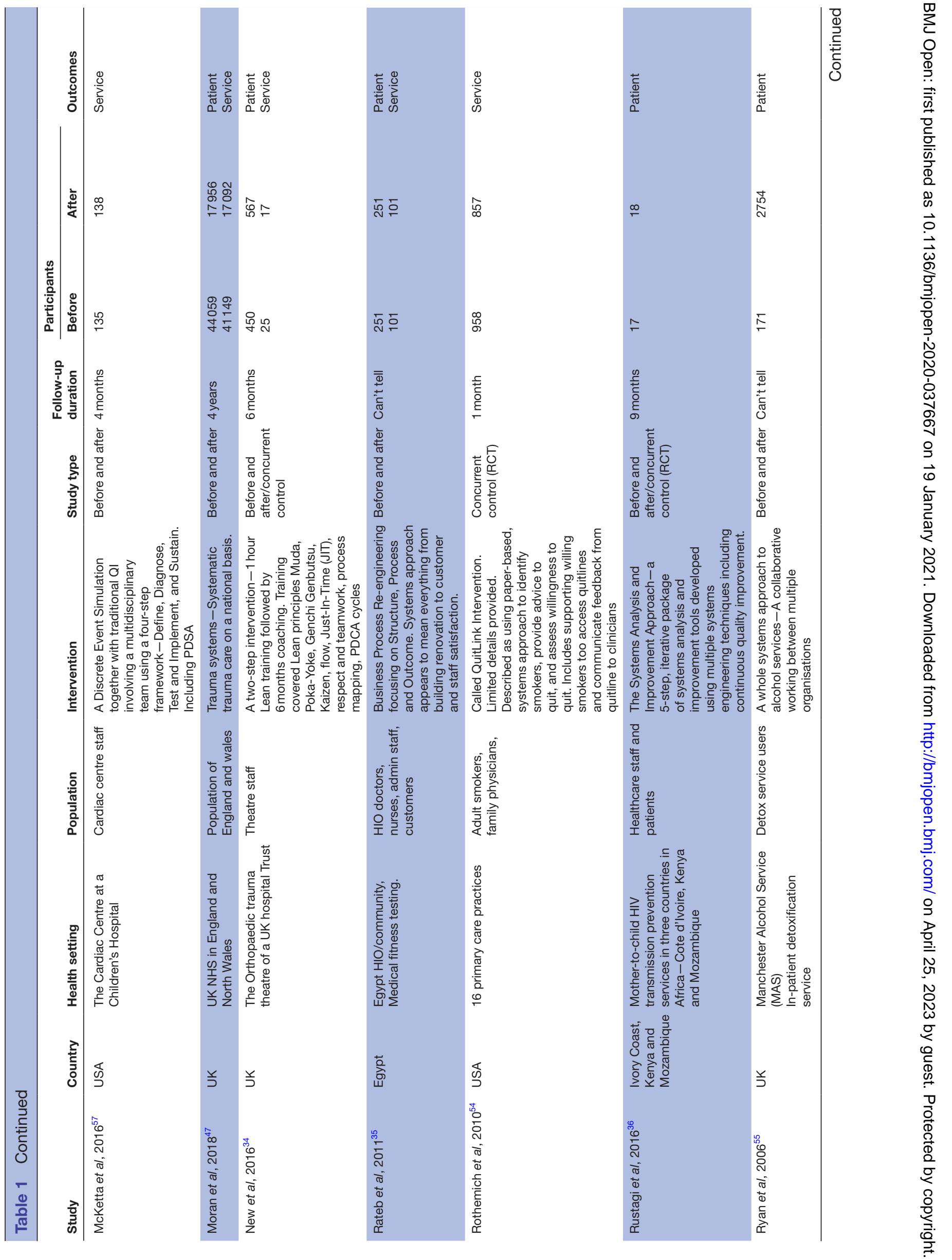




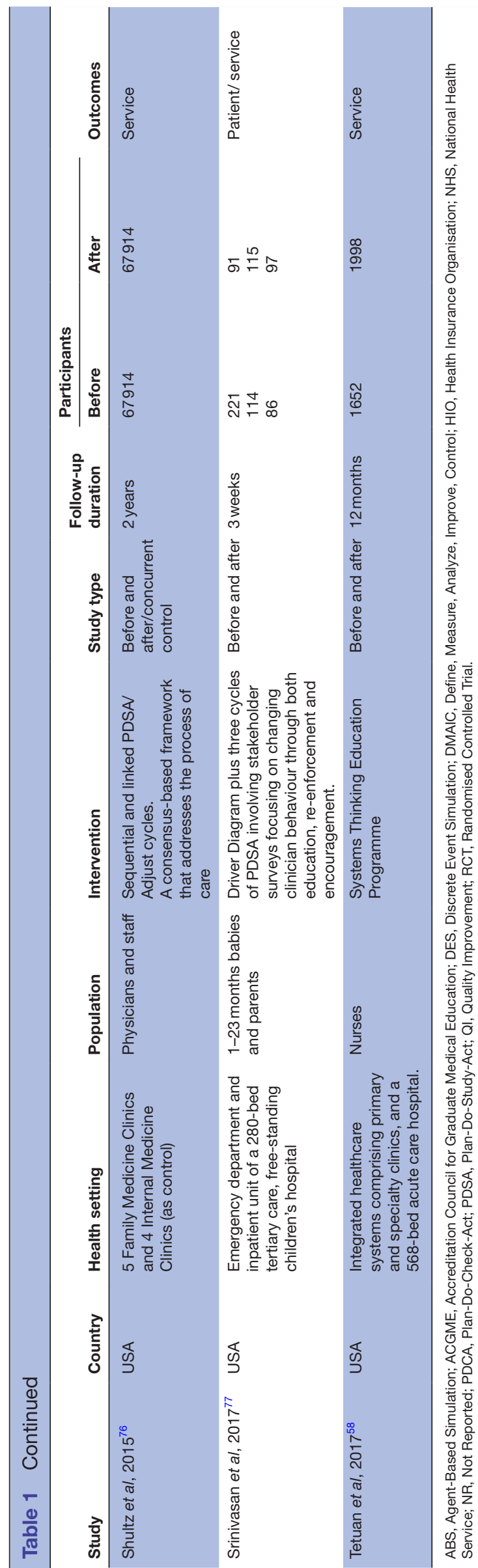

Data collection

A template for data extraction was developed by the research team working through samples of the selected papers to identify relevant fields and tables appropriate to the study question. The data extraction process was designed to include an element of quality control and minimisation of researcher bias. The lead author initially extracted data from all included studies using the agreed template, with other team members each assigned a subset of these to independently corroborate.

Data were extracted into tables as listed below, and all included in online supplemental file 2. Patient outcomes and service outcomes are each separated into two tables according to study design (see online supplemental table S2-S5b). Online supplemental tables S6-S8 are the results of applying the Critical Appraisal Skill Programme $(\mathrm{CASP})^{30}$ questions to included studies:

1. Study source, Country, year and aspects of systems approach.

2. Characteristics of studies (population and intervention).

3. Characteristics of studies (design, baseline type, blinding and funding source).

4. Patient outcomes

1. Patient outcomes for studies with before and after design.

2. Patient outcomes for studies with concurrent design.

5. Service outcomes

1. Service outcomes for studies with before and after design.

2. Service outcomes for studies with concurrent design.

6. CASP questions for appraisal of cohort Studies.

7. CASP questions for appraisal of case-control Studies.

8. CASP questions for appraisal of randomised controlled trials (RCTs).

Examples of patient outcomes include numbers of vaccinations received, numbers of medication events and time to death. Examples of service outcomes include appointment delays, customer flows and time to treatment received. We did not include every outcome as this was impossible. We also did not use summary outcomes as this will give undue weighting to some studies compared with others. Outcomes were selected based on their relevance to the overall objective of the respective studies.

\section{Patient and public involvement}

Due to the focus of this review on synthesising evidence within the academic literature, patient and public involvement was not applicable.

\section{Data analysis}

Review manager (V.5.3, The Cochrane Library) was used for the meta-analyses using a random-effects model due to the heterogeneity of participants, interventions and outcome measures. Meta-analysis was conducted for service outcomes and patient outcomes separately where the categories below had the highest number of studies. 


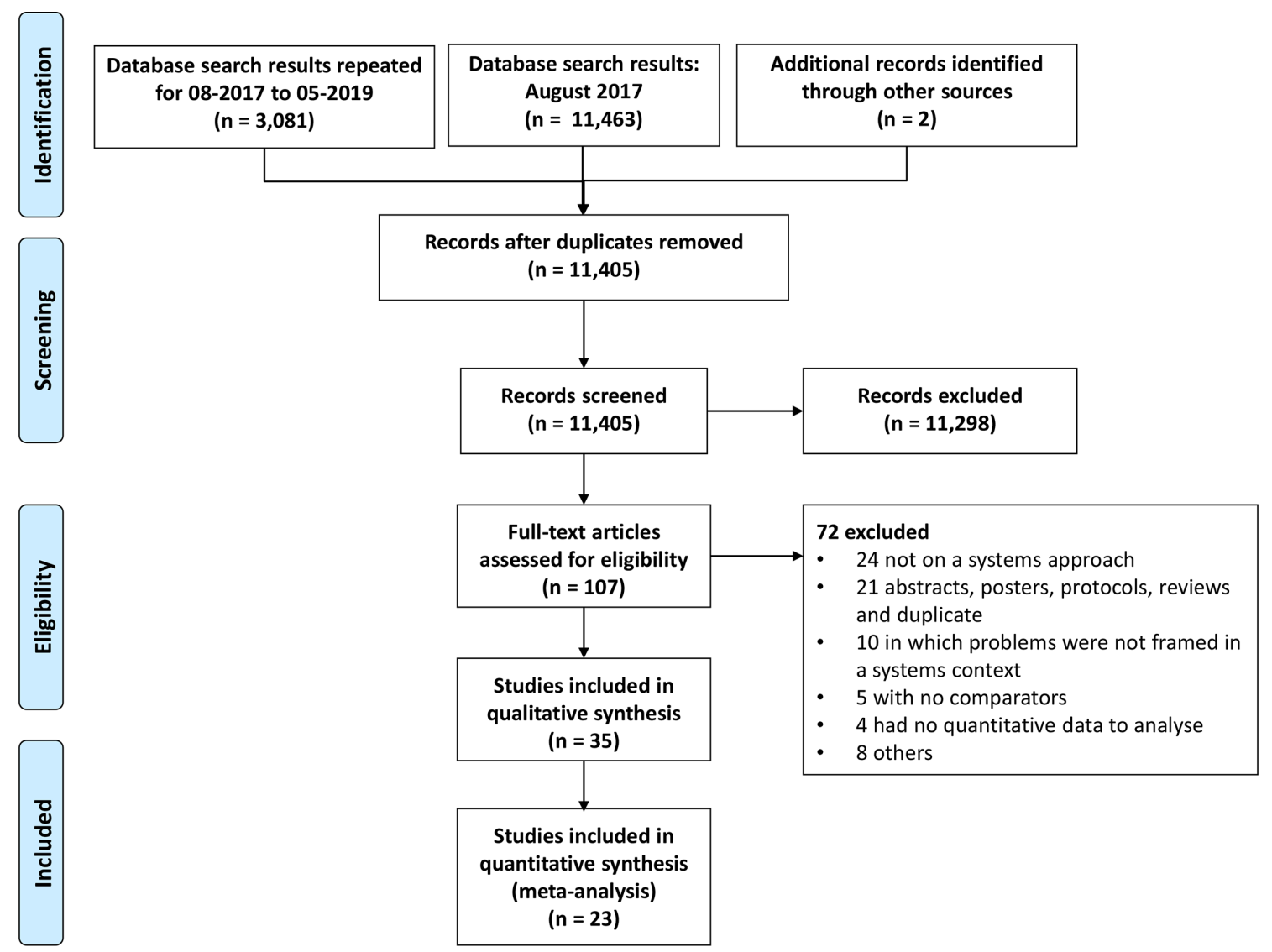

Figure 1 PRISMA systematic review process. PRISMA, Preferred Reporting Items for Systematic Reviews and Meta-Analyses.

Categories were before-and-after studies, studies with concurrent controls and continuous versus categorical versus time-to-event data. The highest numbers of studies for both service and patient outcomes were the beforeand-after studies so this category was used in both metaanalyses. Heterogeneity was assessed using the $\mathrm{I}^{2}$ statistic, using standard thresholds. Risk of publication bias was assessed by use of a funnel plot primarily using the service outcome studies and adding the patient outcome results for studies not already in the service outcome meta-analysis.

Risk of bias for all studies was assessed by two researchers independently using CASP checklists. ${ }^{30}$ These were chosen because they have a suite of checklists appropriate for different study designs. Differences were resolved through a consensus process. The CASP checklist for cohort studies, case control and RCTs were applied accordingly. The checklists consist of 11 or 12 questions in three sections-study validity, study results and local value of results. A complete PRISMA checklist (online supplemental file 4) is also included to illustrate adherence to the review process.

\section{RESULTS}

Our initial search found 11463 records published prior to August 2017 and an extended search in May 2019 found a further 3081 records. After deduplication there were 11405 citations including two records added from personal sources. Of these, 11298 records were excluded after the scanning process, leaving 107 full texts. Included were 35 studies, out of which 23 provided sufficient data for the two meta-analyses conducted (figure 1).

Of the 35 included studies, 28 (80\%) had a before-andafter design only. Six studies had both a before-and-after and concurrent design (including two RCTs). Summary characteristics of included studies are presented in table 1. Studies excluded at the full-text review stage, with reasons for exclusion, are provided in the online supplemental file 3.

There was considerable diversity in how a systems approach was conceptualised and implemented in the included studies. This diversity in approaches may be categorised in three ways:

1. A comprehensive implementation of traditional tools and approaches such as Plan-Do-Study-Act (PDSA), Lean, Human Factors Engineering, WHO health systems strengthening principles, SEIPS model, Business Process Re-engineering, Structure- Process- Outcome and various combinations of these. ${ }^{31-40}$

2. A focus on the breadth of coverage of the intervention, involving a wide range of stakeholders from patients, communities, multiple departments including consideration of physical structures. ${ }^{41-55}$

3. The application of standard systems concepts such as systems thinking and complex adaptive systems theory. ${ }^{56-60}$ 

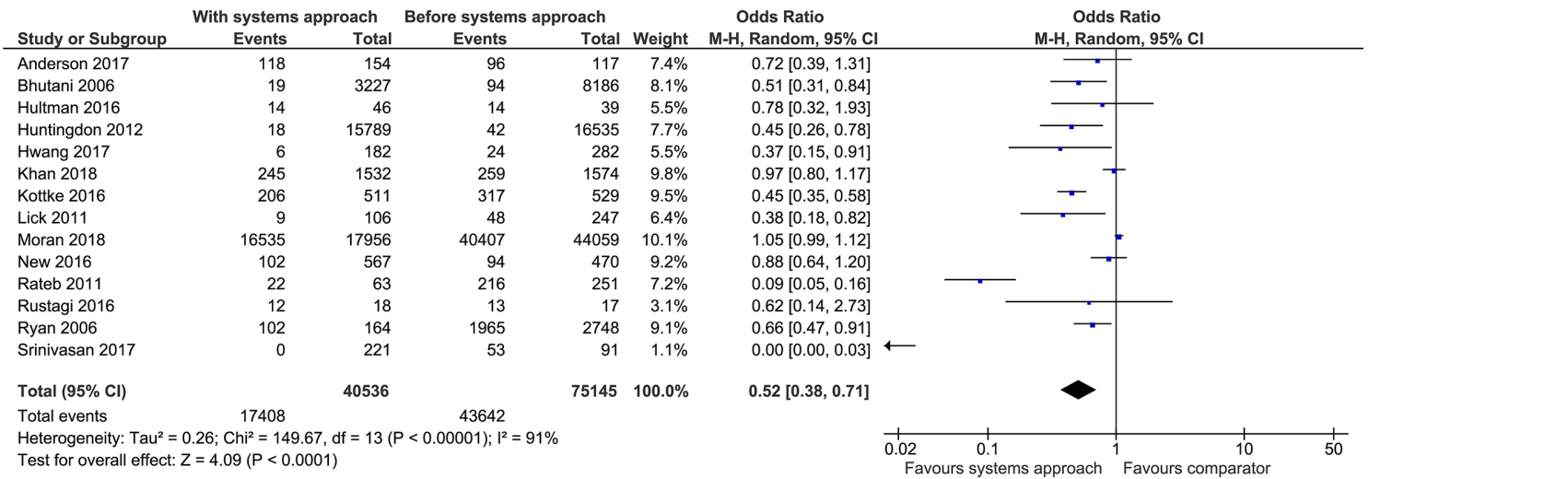

Figure 2 The impact of a systems approach on patient outcomes-before-and-after studies. M-H, Mantel-Haenszel

Almost all included studies showed a benefit for using a systems approach for almost all the outcomes. The exceptions were New et $a l^{34}$ (service outcome, concurrent control) and Dennerlein $e t a t^{99}$ (service outcome, concurrent control). Most of the factors reported as contributing to success were related to people. These were expressed in the form of engaging with stakeholders, taking a teambased approach, enhancing communication, adopting a collaborative approach, patient-centredness and physician-centredness. Similarly, difficulty in measuring impact and the inability to generalise to other contexts emerged as the most significant limitations.

We included two RCTs in our systematic review. Both reported significant improvements in outcomes favouring a systems approach. Rustagi $e t a l^{36}$ randomised 36 health facilities in Cote d'Ivoire, Kenya and Mozambique to usual care or 'a systems engineering intervention' stratified by country and volume. They found that antiretroviral (ARV) coverage for HIV positive women increased threefold in intervention facilities compared with control facilities while HIV-exposed infants screening increased 17-fold. Similarly, Rothemich et $a \bar{l}^{54}$ randomised 16 practices into intervention (8) and control (8) groups to determine whether a systems approach enhances smoking cessation support in primary care practices. The study concluded that a systems approach to identifying smokers, advising, assessing readiness to quit and referral to supporting agencies, led to statistically significant increases in cessation for patients irrespective of gender, compared with traditional tobacco-use vital sign screening alone.

Two exploratory meta-analyses were conducted on categorical outcomes reported in before-and-after studies; one on patient outcomes (figure 2), and one on service and resource use outcomes (figure 3).

Exploratory meta-analysis suggests that a systems approach significantly improves both patient outcomes $\left(\mathrm{n}=14, \mathrm{OR}=0.52 \quad(95 \%\right.$ CI 0.38 to 0.71$\left.) \mathrm{I}^{2}=91 \%\right)$ and service outcomes $(\mathrm{n}=18, \mathrm{OR}=0.40(95 \%$ CI 0.31 to 0.52$)$ $\left.\mathrm{I}^{2}=97 \%\right)$.

Heterogeneity was very high. The funnel plot (figure 4) is unclear regarding publication bias. If anything, it might suggest that small studies with very positive results are missing, rather than those with null results.

It is important that the above results are interpreted with the heterogeneity and the quality of the included studies in mind. The two included RCTs both had reasonably high quality. The five cohort studies with concurrent controls varied between good and fair quality. The beforeand-after studies which made up $80 \%$ of included studies varied widely in quality, ranging from good to very poor. Details of the quality assessment results are included in the last three online supplemental table S5-S7.

\begin{tabular}{|c|c|c|c|c|c|}
\hline \multirow[b]{2}{*}{ Study or Subgroup } & \multicolumn{2}{|c|}{ With systems approach } & \multicolumn{2}{|c|}{ Before systems approach } & \multirow[b]{2}{*}{ Weight } \\
\hline & Events & Total & Events & Total & \\
\hline Anderson 2017 & 3 & 117 & 5 & 154 & $2.4 \%$ \\
\hline Bhatt 2014 & 2 & 17 & 9 & 13 & $1.5 \%$ \\
\hline Bhutani 2006 & 156 & 11995 & 446 & 8186 & $11.4 \%$ \\
\hline Bowen 2016 & 4 & 88 & 30 & 75 & $3.6 \%$ \\
\hline Bradley 2011 & 56 & 140 & 140 & 140 & $0.8 \%$ \\
\hline Dennerlein 2017 & 388 & 2131 & 448 & 2149 & $11.7 \%$ \\
\hline Heymann 2004 & 58 & 1000 & 79 & 1000 & $9.9 \%$ \\
\hline Hwang 2017 & 1 & 182 & 24 & 282 & $1.4 \%$ \\
\hline Lick 2011 & 21 & 106 & 72 & 247 & $7.7 \%$ \\
\hline Loh 2017 & 10 & 39390 & 3 & 6111 & $2.9 \%$ \\
\hline McGrath 2019 & 551 & 557 & 678 & 678 & $0.7 \%$ \\
\hline Moran 2018 & 5572 & 17092 & 16871 & 41149 & $12.2 \%$ \\
\hline New 2016 & 3 & 17 & 9 & 25 & $2.3 \%$ \\
\hline Rateb 2011 & 16 & 36 & 100 & 101 & $1.3 \%$ \\
\hline Rustagi 2016 & 16 & 18 & 17 & 18 & $0.9 \%$ \\
\hline Schultz 2015 & 20917 & 67914 & 20917 & 67914 & $12.2 \%$ \\
\hline Srinivasan 2017 & 11 & 86 & 62 & 97 & $5.8 \%$ \\
\hline Tetuan 2017 & 175 & 1998 & 305 & 1652 & $11.3 \%$ \\
\hline Total $(95 \% \mathrm{Cl})$ & & 142884 & & 129991 & $100.0 \%$ \\
\hline Total events & 27960 & & 40215 & & \\
\hline
\end{tabular}

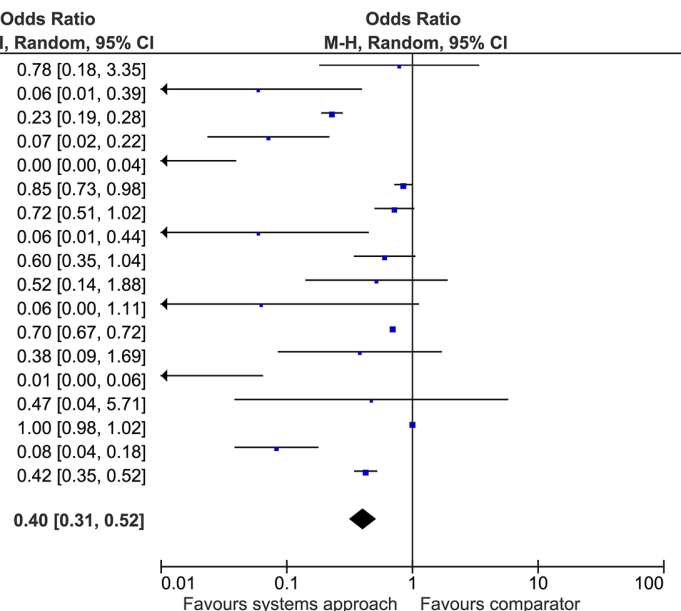

Figure 3 The impact of a systems approach on service and resource use-before-and-after studies. M-H, Mantel-Haenszel 


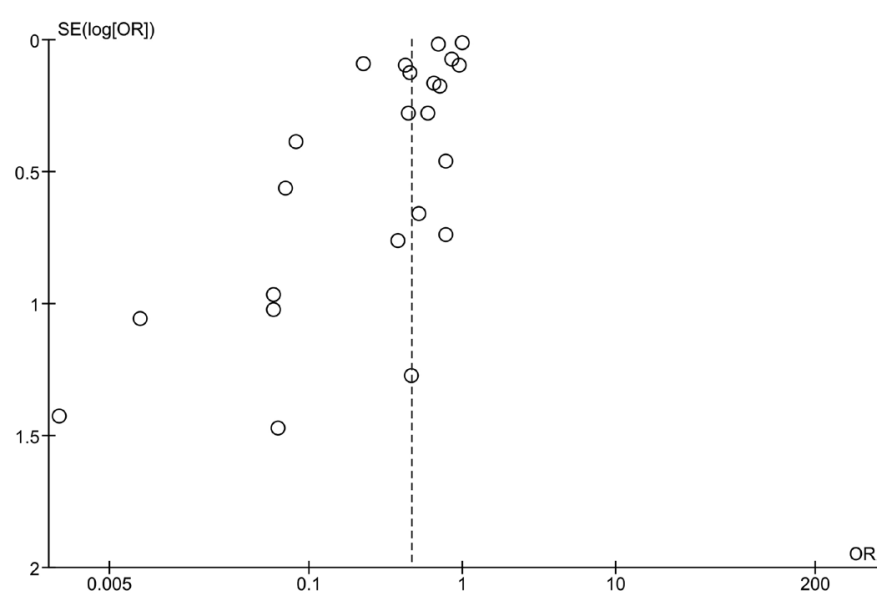

Figure 4 Funnel plot using combined service and patient outcome results.

\section{DISCUSSION}

Our novel systematic review with exploratory metaanalyses suggests that the use of a systems approach to improving care results in significant benefits for both patient and service outcomes. There were two RCTs included that individually found statistically significant improvements in outcomes associated with the use of a systems approach. These findings, together with the observation that the majority of studies had a beforeand-after design, present a challenge in interpretation of results in relation to what is usually considered good quality evidence. In addition, we observed a number of factors, which may support success in the use of a systems approach as reported by the included studies. To our knowledge, this is the first systematic review that has endeavoured to conduct a comprehensive synthesis of the evidence base for a systems approach to healthcare improvement.

This review adds to a growing number of systematic reviews apparently motivated by the desire to find evidence for what works in healthcare improvement. Narrative reviews ${ }^{19-23}$ of a systems approach in healthcare have focused on specific health issues such as patient safety, Human Factors and Ergonomics (HFE) in healthcare, primary care, well-being of health workers and public health. Though these generally demonstrate value of a systems approach, they lack a rigorous and comprehensive assessment of the evidence base for this. Other systematic reviews have been conducted on most of the major healthcare improvement methodologies including Lean, ${ }^{61}$ Six Sigma, ${ }^{61} 62$ PDSA, ${ }^{63}$ Statistical Process Control (SPC) ${ }^{64}$ and Quality Improvement Collaboratives (QIC) ${ }^{65}$ with mixed results. DelliFraine $e t a t^{61}$ in their review of both the Lean and Six Sigma methodologies concluded that there is very weak evidence that either of the methods improves care. However, the review did not provide a meta-analysis of the studies identified and only focused on studies between 1999 and 2009, thus limiting its value. Taylor et $a l^{66}$ in their review of PDSA found poor compliance with the original principles of the methodology but did not aim to assess the impact of the method on outcomes. In the review of SPC, the authors found considerable benefits of using the approach to monitor and control health processes, though they acknowledge some limitations exist. Wells et a ${ }^{65}$ in their review of QICs reported significant improvements in process and patient outcomes. Their review reported outcome measures from included studies but stopped short of a full meta-analysis. Our findings are also consistent with the expectations of positive impact from the several publications that have called for a systems approach to tackling the challenges of modern health delivery systems. ${ }^{10-16}$ There is, clearly, considerable interest in assessing the evidence base of various improvement methodologies, however, existing systematic reviews have not been comprehensive enough and lack focus on patient and service outcomes.

Though the current review focuses on a systems approach to improvement, we believe this represents the most comprehensive systematic review and meta-analysis so far for evidencing the effectiveness of an improvement methodology. This is because we had no limits on date of publication, health setting, study type or participant types. We wanted the results to be relevant to a wide range of healthcare improvements contexts. However, one may object to our decision to combine very heterogeneous studies as we have done because of the differences in clinical settings and outcomes being measured. We reasoned that the results of a combined study would be more useful to the healthcare community, practitioners and policy-makers than an issue-specific systematic review. Moreover, several of those already exist, although not as rigorous. The inclusion of two RCTs in this review further strengthens the results. Though limited in number, both RCTs report statistically significant improvements in outcomes following the implementation of a systems approach.

\section{Limitations}

The major limitation of our study rests on the heterogeneity of the literature it seeks to synthesise, with wide variation in the settings, participants, comparators, follow-up durations and study designs. We have sought to mitigate this using a clearly articulated definition of a systems approach, and a structured, rigorous, approach to synthesising the available evidence. We have conducted just two meta-analyses in order to give an overview of the general direction of results. We acknowledge that the estimated effect size gives an artificial precision which may not be warranted. The heterogeneity of meta-analysis results is to be expected, given the wide variation in participants, settings, interventions, comparators and outcomes. This exploratory meta-analysis can only indicate that a systems approach appears to be beneficial. This benefit must be interpreted and applied with care because the evidence mostly comes from before and after study designs, with inherent confounding factors of unknown magnitude and direction. There is also a significant risk of publication bias, and several included studies also reported both 
the potential of a Hawthorne effect and the existence of other interventions at the time of their study which may have contributed to their observed outcomes. The fact that we selected outcomes based on their relevance to the overall objectives of the studies included may introduce another level of bias if authors framed their objectives based on what they wanted to publish.

\section{Implications for further research}

The engineering sector is one that has excelled in the application of a systems approach. ${ }^{18}$ The experience of the Systems Engineering community is that the value of a systems approach-in terms of quality of the resulting system, reduction in cost, delivery on time, customer satisfaction-corresponds to the extent to which a project or organisation commits to the approach. ${ }^{6768}$ This has implication for our findings in this review. It helps raise a number of questions that present opportunities for future research. For example, what are the different ways in which a systems approach is implemented in healthcare? Is there an association between the time and resource invested in a systems approach and the impact on patient and service outcomes? If so, what is the optimum level of investment?

Another opportunity for future research is a comparative review which assesses the impact of all improvement initiatives against those explicitly adopting a systems approach if more certainty of the value of the approach is desired. Given the volume of literature involved in such a comparative review, this would represent a significant undertaking. Studies are also needed that adopt better study designs such as RCTs or, if necessary, develop alternative ways of understanding and achieving sufficiently robust evidence for a systems approach to healthcare design and delivery. This is a point pertinent to all improvement efforts, where the traditional medical model of the randomised controlled trial is rarely appropriate, but the need to generate convincing evidence remains pressing.

\section{Policy implications}

We have argued from the start that there has been a growing recognition of the potential value of a systems approach to healthcare improvement over the past two decades. Most of this recognition has been at the policy level, involving the $\mathrm{WHO},{ }^{69}$ the Institute of Medicine in the USA, ${ }^{3}{ }^{412}$ the Department of Health in the UK ${ }^{70} 71$ and more recently, through a joint initiative between the Royal Academy of Engineering, Royal College of Physicians and the Academy of Medical Sciences. ${ }^{10}$ However, to support further research and increased practice of a systems approach in health and care, policy-makers need to understand the evidence base. Though several success stories and domain-specific reviews exist, a comprehensive review of the evidence across the healthcare literature has been lacking. Our review may, therefore, become invaluable to policy-makers who have found the argument for a systems approach conceptually appealing but also desire to see the evidence of what difference such an approach can make to patient and service outcomes. In addition, the references taken individually may serve as examples of real-world applications of a systems approach to healthcare improvement.

\section{CONCLUSIONS}

In summary, we have argued that a systems approach to healthcare has been championed increasingly in the health and care literature and in a variety of grey literature reports and position documents. We provide the first attempt to comprehensively explore the evidence base through a systematic review and meta-analysis. The results provide reasonably clear evidence that a systems approach to addressing health delivery challenges may lead to significant improvements in both patient and service outcomes.

\section{Author affiliations}

${ }^{1}$ Department of Engineering, University of Cambridge, Cambridge, UK

${ }^{2}$ The Healthcare Improvement Studies (THIS) Institute, University of Cambridge,

Cambridge, UK

${ }^{3} \mathrm{NIHR}$ Global Health Research Group on Neurotrauma, Cambridge University Hospitals NHS Foundation Trust, Cambridge, UK

${ }^{4}$ Division of Anaesthesia, Cambridge University Hospitals NHS Foundation Trust, Cambridge, UK

${ }^{5}$ Faculty of Engineering and Natural Sciences, Istanbul Medeniyet University, Istanbul, Turkey

${ }^{6}$ School of Clinical Medicine, University of Cambridge, Cambridge, UK

${ }^{7}$ Media and Visual Arts, Koc University, Istanbul, Turkey

${ }^{8}$ Primary Care Unit, Department of Public Health and Primary Care, University of Cambridge, Cambridge, UK

${ }^{9}$ Major Trauma Unit, Cambridge University Hospitals NHS Foundation Trust, Cambridge, UK

${ }^{10}$ Department of Care Quality Improvement, Royal College of Physicians, London, UK ${ }^{11}$ School of Nursing and Midwifery, Anglia Ruskin University - Cambridge Campus, Cambridge, UK

Twitter Alexander Komashie @AlexanderDotKom, Isla Kuhn @ilk21 and Eugenia 0'Kelly @eugeniaokelly

Acknowledgements The authors would like to thank the National Institute for Health Research (NIHR) Collaboration for Leadership in Applied Health Research and Care for the East of England (CLAHRC EoE) for providing financial support for some members of the team during this work. Our sincere thanks also go to Dr Nathan Crilly at the University of Cambridge Engineering Department, and Dr Guillaume Lamé of CentraleSupélec, Paris, for their constructive review of versions of the manuscript and finally to Paul Driver of Anglia Ruskin University, Cambridge for help with improving the quality of our images.

Contributors AK, TD and JW conceived the idea for the study. All authors were involved in discussions that informed the design of the study and development of the search strategy. IK conducted the database search and sourced full texts of included studies. AK, TB, JW, TD, GKK and YL did the record scanning. The full-text review was done by AK, TB, JW, TD, GKK, YL, AG, JM and EO. Data extraction was undertaken by AK, TB, JW, TD, GKK, YL, AG, JM and KK. The meta-analysis and interpretation were done by $\mathrm{CM}$ and initial results discussed by all authors. Qualitative synthesis of included studies was conducted by AG, AK and NB whilst quality of studies were appraised by KK, AG, AK, GKK, YL, TB, JW and JM. Manuscript writing was led by AK, TB, CM, AG, PJC, JD, EO with contributions from all authors. Final approval of manuscript has been obtained from all authors. AK is the guarantor of this study.

Funding This research was funded by the National Institute for Health Research (NIHR) Global Health Research Group on Neurotrauma using UK aid from the UK Government to support global health research, and by The Healthcare Improvement Studies Institute (THIS Institute), University of Cambridge. THIS Institute is supported by the Health Foundation, an independent charity committed to bringing about 
better health and healthcare for people in the UK. The views expressed in this publication are those of the authors and not necessarily those of the NIHR or the UK government.

Competing interests AK reports grants funding from The Healthcare Improvement Studies (THIS) Institute and the NIHR Global Health Research Group on Neurotrauma. JW reports grants from National Institute for Health Research and the University of Cambridge, during the conduct of the study. TB reports grants from NIHR Global Health Research Group on Neurotrauma, during the conduct of the study. TD reports grants from NIHR CLAHRC East of England, during the conduct of the study. All other authors declare no competing interests.

Patient consent for publication Not required.

Provenance and peer review Not commissioned; externally peer reviewed.

Data availability statement All data relevant to the study are included in the article or uploaded as online supplemental information. No additional data are available.

Supplemental material This content has been supplied by the author(s). It has not been vetted by BMJ Publishing Group Limited (BMJ) and may not have been peer-reviewed. Any opinions or recommendations discussed are solely those of the author(s) and are not endorsed by BMJ. BMJ disclaims all liability and responsibility arising from any reliance placed on the content. Where the content includes any translated material, BMJ does not warrant the accuracy and reliability of the translations (including but not limited to local regulations, clinical guidelines, terminology, drug names and drug dosages), and is not responsible for any error and/or omissions arising from translation and adaptation or otherwise.

Open access This is an open access article distributed in accordance with the Creative Commons Attribution Non Commercial (CC BY-NC 4.0) license, which permits others to distribute, remix, adapt, build upon this work non-commercially, and license their derivative works on different terms, provided the original work is properly cited, appropriate credit is given, any changes made indicated, and the use is non-commercial. See: http://creativecommons.org/licenses/by-nc/4.0/.

\section{ORCID iDs}

Alexander Komashie http://orcid.org/0000-0002-0715-4729

Tom Bashford http://orcid.org/0000-0003-0228-9779

Gulsum Kubra Kaya http://orcid.org/0000-0003-0663-3995

Yuanyuan Liu http://orcid.org/0000-0003-2331-2392

Aslı Günay http://orcid.org/0000-0002-5261-5889

Katharina Kohler http://orcid.org/0000-0003-1919-0193

Eugenia 0'Kelly http://orcid.org/0000-0002-4748-3957

Catherine Meads http://orcid.org/0000-0002-2368-0665

P John Clarkson http://orcid.org/0000-0001-8018-7706

\section{REFERENCES}

1 Koop CE. Health and health care for the 21st century: for all the people. Am J Public Health 2006;96:2090-2.

2 Majumder S, Aghayi E, Noferesti M, et al. Smart homes for elderly Healthcare-Recent advances and research challenges. Sensors 2017;17. doi:10.3390/s17112496. [Epub ahead of print: 31 Oct 2017].

3 Kohn LT, Corrigan J, Donaldson MS. To err is human: building a safer health system. National Academy Press, 2000.

4 Institute of Medicine (IOM). Crossing the Quality Chasm Crossing the Quality Chasm: A New Health System for the 21st Century. National Academies Press, 2001.

5 Dixon-Woods M, Pronovost PJ. Patient safety and the problem of many hands. BMJ Qual Saf 2016;25:485-8.

6 Onder G, Palmer K, Navickas R, et al. Time to face the challenge of multimorbidity. A European perspective from the joint action on chronic diseases and promoting healthy ageing across the life cycle (JA-CHRODIS). Eur J Intern Med 2015;26:157-9.

7 Plsek PE, Greenhalgh T. Complexity science: the challenge of complexity in health care. BMJ 2001;323:625-8.

8 Dixon-Woods M, McNicol S, Martin G. Ten challenges in improving quality in healthcare: lessons from the health Foundation's programme evaluations and relevant literature. BMJ Qual Saf 2012;21:876-84.

9 Vaughn VM, Saint S, Krein SL, et al. Characteristics of healthcare organisations struggling to improve quality: results from a systematic review of qualitative studies. BMJ Qual Saf 2019;28:74-84.

10 et alClarkson PJ, Bogle D, Dean J. Engineering Better Care: A Systems Approach to Health and Care Design and Continuous
Improvement, 2017. Available: http://www.raeng.org.uk/news/newsreleases/2017/september/healthcare-professionals-and-engineerspartner-to

11 Clarkson J, Dean J, Ward J, et al. A systems approach to healthcare: from thinking to -practice. Future Healthc J 2018;5:151-5.

12 Reid PP, Compton WD, Grossman JH. Building a better delivery system: a new Engineering/Health care partnership, 2005.

13 Swanson RC, Cattaneo A, Bradley E, et al. Rethinking health systems strengthening: key systems thinking tools and strategies for transformational change. Health Policy Plan 2012;27 Suppl 4:iv54-61 http://ovidsp.ovid.com/ovidweb.cgi?T=JS\&PAGE=reference\&D= med7\&NEWS $=$ N\&AN=23014154

14 Mutale W, Bond V, Mwanamwenge MT, et al. Systems thinking in practice: the current status of the six who building blocks for health system strengthening in three BHOMA intervention districts of Zambia: a baseline qualitative study. BMC Health Serv Res 2013;13:291 http://ovidsp.ovid.com/ovidweb.cgi?T=JS\&PAGE= reference\&D=medI\&NEWS $=\mathrm{N} \& A N=23902601$

15 Kaplan G, Bo-Linn G, Carayon P. Bringing a systems approach to health. IOM Discuss Pap 2013;Published online:1-26 http://www. iom.edu/systemsapproaches

16 Clarkson PJ, Buckle P, Coleman R, et al. Design for patient safety: a review of the effectiveness of design in the UK health service. Journal of Engineering Design 2004;15:123-40.

17 NHS. The NHS long term plan. 364, 2019.

18 Elliott C, Deasley P. Creating systems that work: principles of engineering systems for the 21st century. R Acad Eng 2007:293074.

19 Waterson P. A critical review of the systems approach within patient safety research. Ergonomics 2009;52:1185-95 http://ovidsp.ovid. com/ovidweb.cgi?T=JS\&PAGE=reference $\& D=$ med6\&NEWS $=\mathrm{N} \& A N=$ 19787499

20 Xie A, Carayon P. A systematic review of human factors and ergonomics (HFE)-based healthcare system redesign for quality of care and patient safety. Ergonomics 2015;58:33-49.

21 Sturmberg JP, Martin CM, Katerndahl DA. Systems and complexity thinking in the general practice literature: an integrative, historical narrative review. Ann Fam Med 2014;12:66-74.

22 Brand SL, Thompson Coon J, Fleming LE, et al. Whole-system approaches to improving the health and wellbeing of healthcare workers: a systematic review. PLoS One 2017;12:e0188418-26.

23 Chughtai S, Blanchet K. Systems thinking in public health: a bibliographic contribution to a meta-narrative review. Health Policy Plan 2017;32:czw159-94.

24 Forrester JW. Counterintuitive behavior of social systems a new approach to social systems. Technol Forecast Soc Change 1971;22:1-22.

25 Maier MW, Rechtin E. The Art of Systems Architecting. 2nd ed, 2000 https://sdincose.org/wp-content/uploads/2017/10/TheArtOfSyst emsEngineering inaugural.pdf

26 Chen GKC. What is the systems approach? Interfaces 1975;6:32-7.

27 NASA. NASA Systems Engineering Handbook. NASA, 1995.

28 Maier MW, Rechtin E. The Art of Systems Architecting. 2nd ed, 2000.

29 Moher D, Liberati A, Tetzlaff J, et al. Preferred reporting items for systematic reviews and meta-analyses: the PRISMA statement. PLoS Med 2009;6:e1000097.

30 CASP qualitative research checklist, 2018. Available: https://casp-uk. net/wp-content/uploads/2018/03/CASP-Cohort-Study-Checklist2018_fillable_form.pdf [Accessed May 11, 2019].

31 Afsar-Manesh N, Lonowski S, Namavar AA. Leveraging lean principles in creating a comprehensive quality program: the UCLA health readmission reduction initiative. Healthc 2017;5:194-8.

32 Catchpole K, Ley E, Wiegmann D, et al. A human factors subsystems approach to trauma care. JAMA Surg 2014;149:962-8.

33 Loh HP, de Korne DF, Chee SP, et al. Reducing wrong intraocular lens implants in cataract surgery- 3 years of experience with the SEIPS framework in Singapore. Int J Healthc Qual Assur 2017;30:492-505.

34 New S, Hadi M, Pickering S, et al. Lean participative process improvement: outcomes and obstacles in trauma orthopaedics. PLoS One 2016;11:e0152360-13.

35 Rateb SAH, El Nouman AAR, Rateb MAH, et al. Re-Engineering pre-employment check-up systems: a model for improving health services. Int J Health Care Qual Assur 2011;24:484-97.

36 Rustagi AS, Gimbel S, Nduati R, et al. Implementation and operational research: impact of a systems engineering intervention on PMTCT service delivery in Côte d'Ivoire, Kenya, Mozambique: a cluster randomized trial. J Acquir Immune Defic Syndr 2016;72:e68-76 http://journals.Iww.com/jaids/pages/default.aspx

37 Allaudeen N, Vashi A, Breckenridge JS, et al. Using lean management to reduce emergency department length of stay for medicine admissions. Qual Manag Health Care 2017;26:91-6. 
38 Cochran D, Swartz J, Elahi B, et al. Using the collective system design methodology to improve a medical center emergency room performance. J Med Syst 2018;42:242.

39 DeFlitch C, Geeting G, Paz HL. Reinventing emergency department flow via healthcare delivery science. HERD 2015;8:105-15.

40 Chandrasekar T, Sharma A, Tennent L, et al. A whole system approach to improving mortality associated with acute kidney injury. QJM 2017;110:657-66.

41 Bhatt AS, Carlson GW, Deckers PJ. Improving operating room turnover time: a systems based approach. J Med Syst 2014;38:148.

42 Bhutani VK, Johnson LH, Schwoebel A, et al. A systems approach for neonatal hyperbilirubinemia in term and near-term newborns. $J$ Obstet Gynecol Neonatal Nurs 2006;35:444-55.

43 Anderson ME, Mcdevitt K, Cumbler E, et al. Geriatric hip fracture care: fixing a fragmented system. Perm J 2017;21:1-9.

44 Bell R, Glinianaia SV, Waal Zvander, et al. Evaluation of a complex healthcare intervention to increase smoking cessation in pregnant women: interrupted time series analysis with economic evaluation. Tob Control 2018;27:90-8.

45 Bowen M, Prater A, Safdar NM, et al. Utilization of workflow process maps to analyze gaps in critical event notification at a large, urban Hospital. J Digit Imaging 2016;29:420-4.

46 Khan A, Spector ND, Baird JD, et al. Patient safety after implementation of a coproduced family centered communication programme: multicenter before and after intervention study. BMJ 2018;363:k4764.

47 Moran CG, Lecky F, Bouamra O, et al. Changing the System - Major Trauma Patients and Their Outcomes in the NHS (England) 2008-17. EClinicalMedicine 2018;2-3:13-21.

48 Bradley E, Thompson JW, Byam P, et al. Access and quality of rural healthcare: Ethiopian millennium rural initiative. Int J Qual Health Care 2011;23:222-30

49 Dennerlein JT, O'Day ET, Mulloy DF, et al. Lifting and exertion injuries decrease after implementation of an integrated hospital-wide safe patient handling and mobilisation programme. Occup Environ Med 2017;74:336-43.

50 Hathout L, Tenbergen T, Giannouli E, et al. Applying systems engineering to create a population-centered sleep disorders program. Leadersh Health Serv 2013;26:196-203.

51 Heymann AD, Azuri J, Kokia E, et al. Systematic Inventive thinking: a new tool for the analysis of complex problems in medical management. Isr Med Assoc J 2004;6:67-9.

52 Hwang WS, Park JS, Kim SJ, et al. A system-wide approach from the community to the hospital for improving neurologic outcomes in out-of-hospital cardiac arrest patients. Eur J Emerg Med 2017;24:87-95

53 Lick CJ, Aufderheide TP, Niskanen RA, et al. Take heart America: a comprehensive, community-wide, systems-based approach to the treatment of cardiac arrest. Crit Care Med 2011;39:26-33.

54 Rothemich SF, Woolf SH, Johnson RE, et al. Promoting primary care smoking-cessation support with quitlines: the QuitLink randomized controlled trial. Am J Prev Med 2010;38:367-74.

55 Ryan T, Webb L, Meier PS. A systems approach to care pathways into in-patient alcohol detoxification: outcomes from a retrospective study. Drug Alcohol Depend 2006;85:28-34.

56 Kottke TE, Huebsch JA, Mcginnis P, et al. Using principles of complex adaptive systems to implement secondary prevention of coronary heart disease in primary care. Perm J 2016;20:17-24 http:// ovidsp.ovid.com/ovidweb.cgi?T=JS\&PAGE=reference\&D=medl\& NEWS=N\&AN=26784851
57 McKetta D, Day TE, Jones V, et al. Managing disruptions to patient flow capacity: Rapid-cycle improvement in a pediatric cardiac procedure complex. Jt Comm J Qual Patient Saf 2016;42:321-4.

58 Tetuan T, Ohm R, Kinzie L, et al. Does systems thinking improve the perception of safety culture and patient safety? J Nurs Regul 2017;8:31-9.

59 McGrath SP, Perreard IM, Garland MD, et al. Improving patient safety and clinician workflow in the general care setting with enhanced surveillance monitoring. IEEE J Biomed Heal Inform 2019;23:857-66.

60 Kane EM, Scheulen JJ, Püttgen A, et al. Use of systems engineering to design a hospital command center. Jt Comm J Qual Patient Saf 2019;45:370-9.

61 DelliFraine JL, Langabeer JR, Nembhard IM. Assessing the evidence of six sigma and lean in the health care industry. Qual Manag Health Care 2010;19:211-25.

62 Feng $\mathrm{Q}$, Manuel $\mathrm{CM}$. Under the knife: a national survey of six sigma programs in US healthcare organizations. Int $J$ Health Care Qual Assur 2008;21:535-47.

63 Taylor MJ, McNicholas C, Nicolay C, et al. Systematic review of the application of the plan-do-study-act method to improve quality in healthcare. BMJ Qual Saf 2014:23:290-8.

64 Thor J, Lundberg J, Ask J, et al. Application of statistical process control in healthcare improvement: systematic review. Qual Saf Heal Care 2007;16:387-99.

65 Wells S, Tamir O, Gray J, et al. Are quality improvement collaboratives effective? A systematic review. BMJ Qual Saf 2018;27:226-40

66 Taylor MJ, McNicholas C, Nicolay C, et al. Systematic review of the application of the plan-do-study-act method to improve quality in healthcare. BMJ Qual Saf 2014;23:290-8.

67 Honour EC. Technical report: value of systems engineering, 2004.

68 Beasley R. Realizing the value of systems engineering. INCOSE Int Symp 2017;27:1100-13.

69 WHO. Health systems: improving performance, 2000.

70 Department of Health,, Design Council. Design for patient safety: a system-wide Design-Led approach to tackling patient safety in the NHS, 2003.

71 Department of Health. Learning from Bristol: The Department of Health's Response to the Report of the Public Inquiry into the Death of Children's Heart Surgery at Bristol Royal Infirmary, 2002: 1984-95.

72 Gupta A, Li J, Tawfik B, et al. Reducing wait time between admission and chemotherapy initiation. J Oncol Pract 2018;14:e316-23.

73 Hultman CS, Kim S, Lee CN, et al. Implementation and analysis of a lean six sigma program in microsurgery to improve operative throughput in perforator flap breast reconstruction. Ann Plast Surg 2016;76 Suppl 4:S352-6.

74 Huntington D, Banzon E, Recidoro ZD. A systems approach to improving maternal health in the Philippines. Bull World Health Organ 2012;90:104-10 http://ovidsp.ovid.com/ovidweb.cgi?T=JS\&PAGE= reference\&D=med7\&NEWS=N\&AN=22423161

75 Loh HP, Frans de Korne D, Chee SP. Reducing wrong intraocular lens implants in cataract surgery : 3 years pf experience with the SIEPS framework in Singapore. Int J Health Care Qual Assur 2017;30:492-505.

76 Shultz CG, Malouin JM, Green LA, et al. A systems approach to improving tdap immunization within 5 community-based family practice settings: working differently (and better) by transforming the structure and process of care. Am J Public Health 2015;105:1990-7.

77 Srinivasan M, Pruitt C, Casey E, et al. Quality improvement initiative to increase the use of nasogastric hydration in infants with bronchiolitis. Hosp Pediatr 2017;7:436-43. 